\title{
Removal of organic solvents for the purpose of manufacturing of solvent- free pressure-sensitive adhesives
}

\author{
${ }^{1}$ Zbigniew Czech, ${ }^{2}$ Roland Milker, ${ }^{1}$ Agnieszka Butwin, ${ }^{1}$ Ewa Herko \\ ${ }^{1}$ Szczecin University of Technology, Institute of Chemical Organic Technology, ul. Pulaskiego 10, 70-322 Szczecin, Poland, \\ e-mail: psa_czech@wp.pl \\ ${ }^{2}$ Roland Milker, ChemCycle Bitterfeld, Chemiepark Bitterfeld-Wolfen, D-06803 Greppin, Germany
}

\begin{abstract}
The present report reports on the process of the removal of organic solvents in the polymerisation reactor, thin-layer evaporator, and twin-screw extruder for the production of the solvent-free acrylic pressure-sensitive adhesives (PSA). New applications and technical specifications stimulate the continuous development of new methods of manufacturing of non-solvent self-adhesives. The new synthesis of $100 \%$ acrylic systems includes solvent polymerisation and finally a removal of volatile organic compounds in a special extruder, polymerisation vessel or an industrial evaporator. The removal process requires controlling such relevant parameters as temperature, pressure and volatile organic compounds concentration.
\end{abstract}

Keywords: PSA, removal of solvent, polymerisation reactor, evaporator, extruder, acrylic.

Presented at the XIX Polish Conference of Chemical and Process Engineering in Rzeszów, Poland, 3 - 7 September 2007.

\section{INTRODUCTION}

The term pressure-sensitive adhesives (PSA) is described by a very precise technical definition and is used extensively in chemical literature ${ }^{1}$. The function of PSA is to ensure instantaneous adhesion upon the application of a light pressure. The properties, which are essential in characterizing the nature of PSA, comprise: tack (initial adhesion), peel adhesion (adhesion), and shear (cohesion) $)^{2}$. Pressure-sensitive adhesives are used for various products represented by adhesive tapes, labels, protective and decorative foils, and medical pads. The hot-melt kinds, dispersion kinds, and other technologies for non-solvent PSA are being realised as part of the PSA applications ${ }^{3}$.

These three different manufacture processes that are industrially applied, include:

- polymerization in the reactor with a removal of the volatile solvent,

- polymerization in the twin-screw extruder and a removal of volatile compounds,

- polymerization in the thin-layer evaporator and a removal of organic volatile compounds.

\section{EXPERIMENTAL}

The following experiments were conducted in order to study the diverse polymerisation technologies in combination with the removal of organic solvent and volatile free monomers. The most important parameters were: screw speed during the polymerisation in the extruder and other important properties of the polymerisation process such as acrylic PSA viscosity, acrylic PSA yield and the polymerisation conversion.

According to polymerisation technology the basic acrylic PSA was synthesised by using 2-ethylhexyl acrylate (44.5 wt.\%), butyl acrylate (30 wt.\%), methyl acrylate (20 wt.\%), acrylic acid (5 wt.\%) and $0.5 \mathrm{wt} . \%$ of unsaturated photoinitiator 4acryloyloxy benzophenone. The polymerisation process was initiated with $0.1 \mathrm{wt} . \%$ radical starter 2,2'-azo-diisobutyronitrile in the mixture acetone/ethyl acetate (50:50) with $50 \mathrm{wt} . \%$ monomers content.

2-Ethylhexyl acrylate, butyl acrylate, methyl acrylate, acrylic acid and 2,2'-azo-diisobutyronitrile are available from Tokyo
Chemical Industry Co. The unsaturated photoinitiator 4acryloyloxy benzophenone was synthesised at ChemCycle (Germany).

The viscosity of the PSA synthesized in the extruder was measured with a viscometer RM 180 Rheomat, from Rheometric Scientific Company.

The molecular weight studies were performed in tetrahydrofurane with a liquid chromatograph LaChrom system: RI Detector L-7490 and LaChrom UV Detector L-7400 from Merck-Hitachi, equipped with a PLgel $10^{6} \AA$ column from Hewlett-Packard.

The examined photoreactive UV-crosslinked pressure-sensitive adhesives were cured with an ultraviolet light lamp $\mathrm{U}$ 350-M-I-DL from IST Company with a UV-A wavelength between 315 and $380 \mathrm{~nm}$. The UV-exposure can be measured by using an integrating radiometer Dynachem ${ }^{\mathrm{TM}}$ Model 500, available from Dynachem Corporation, 2631 Michelle Drive, Tustin, CA 92680.

Tack, adhesion and cohesion of the investigated acrylic pressure-sensitive adhesives were tested according to A.F.E.R.A. 4015 (tack), 4001 (adhesion) and 4012 (cohesion) procedures.

\section{RESULTS AND DISCUSSION}

\section{Polymerisation in the reactor with the removal of the sol-} vent

According to this technology the synthesis of acrylic PSA takes place in an organic solvent with a low boiling point (e.g. ethyl acetate, hexane, acetone) using an unsaturated photoinitiator, being incorporated covalently into a polymer chain during the polymerisation process. The polymerisation medium is then removed under vacuum at high temperature. The resultant polymer is then, in a manner similar to a classical solvent-free hot-melt adhesive, coated at high temperature $\left(100-150^{\circ} \mathrm{C}\right)$ and cross-linked in seconds or minutes with UV radiation (UV-lamps) (Fig. 1) ${ }^{4}$.

This concept is based on the well-tested techniques and runs with the least risks. The removed solvent can be used again for the polymerisation process ${ }^{5}$. 


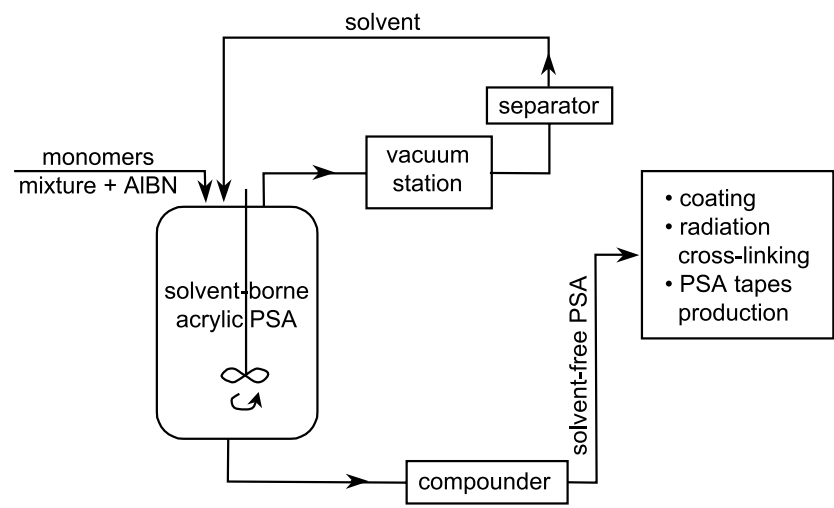

Figure 1. A batch synthesis concept of the solvent-free acrylic PSA

Presently, this method seems to be a useful way of manufacturing the solvent-free acrylic PSA hot-melts from solvent based systems.

From the previous investigations of the acrylic PSA it is known that the viscosity of the solvent-borne acrylic PSA with $50 \mathrm{wt} . \%$ solid content greater than about 3000 to $3500 \mathrm{mPa} \cdot \mathrm{s}$, can lead to problems with a complete evaporation of the solvent and free monomers from the polymer solution. The solvent-free acrylic hot-melt PSA products resulted from the solvent-borne PSA with the viscosity greater than about 4000 $\mathrm{mPa} \cdot \mathrm{s}$, after the high viscous and melt-able above $160^{\circ} \mathrm{C}$ degassing process. At this temperature the process of heat degradation of acrylic PSA begins. The viscosity of the solvent-free PSA is determinated to the viscosity of the solventborne acrylic PSA (Fig. 2) and the viscosity of the solventborne acrylic PSA depends on the molecular weight of the solvent-borne PSA (Fig. 3).

The solvents (acetone, ethyl acetate) and free monomers are removed and the solvent- free highly viscous material can be processed on a hot-melt coating machine at the temperatures between 100 and $150^{\circ} \mathrm{C}$. Higher temperature (approx. $150^{\circ} \mathrm{C}$ ) applied over an extended period ( 24 hours) had no adverse effect on the adhesive properties.

The removal process of volatile organic compounds (VOC), of the solvent-borne acrylic PSA in the polymerisation reactor was conducted in two steps, which are presented in Fig. $4^{6}$ :

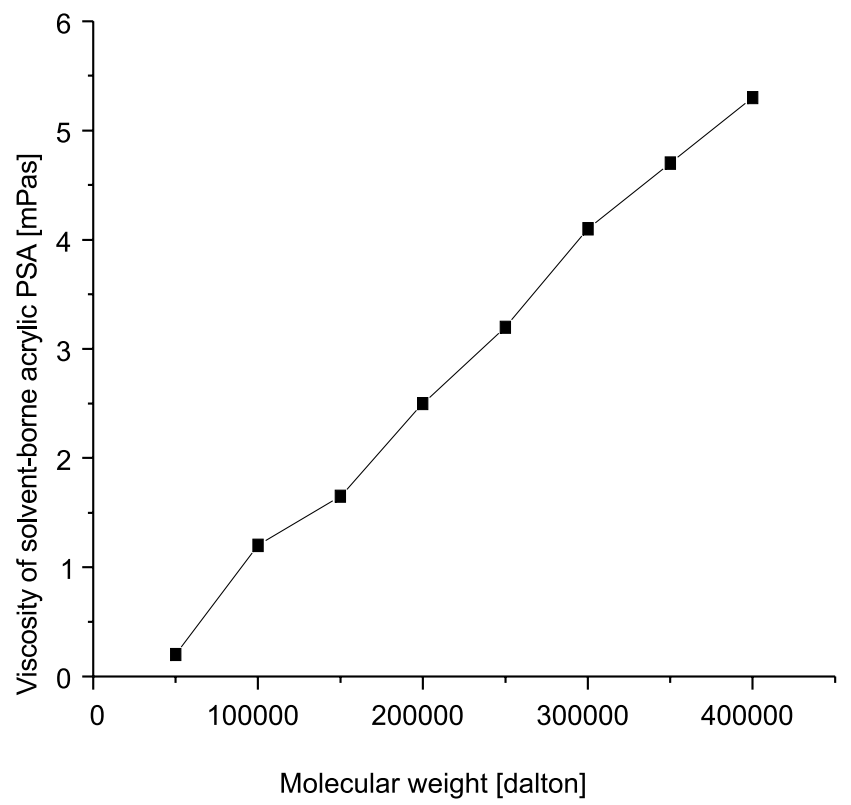

Figure 2. The viscosity of the solvent-borne acrylic PSA versus the molecular weight

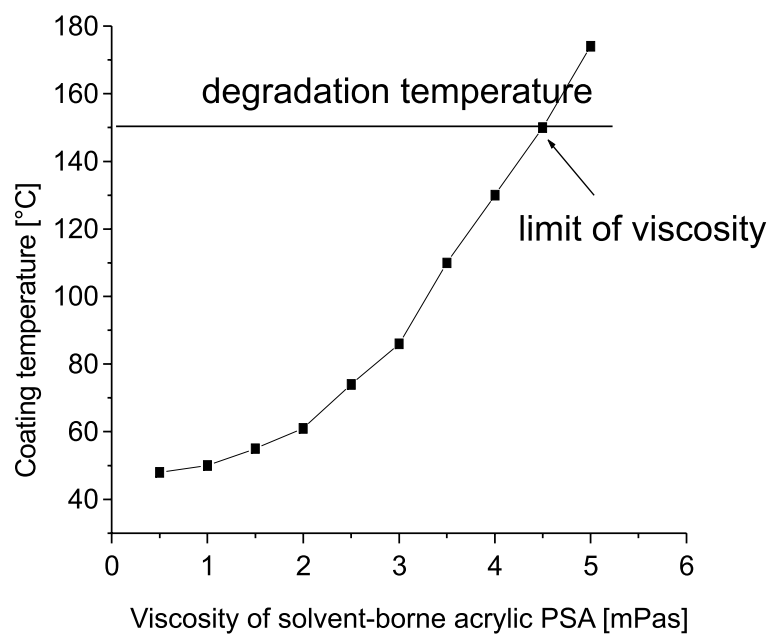

Figure 3. The coating temperature of hot-melt acrylics versus the viscosity of the solvent-borne acrylics

- first step: degassing under atmospheric pressure at the temperature between 100 and $120^{\circ} \mathrm{C}$ (measurement of the removed volatile compounds)

- second step: degassing under vacuum $<20-30 \mathrm{~mm} \mathrm{Hg}$ (measurement of the removed volatile compounds).

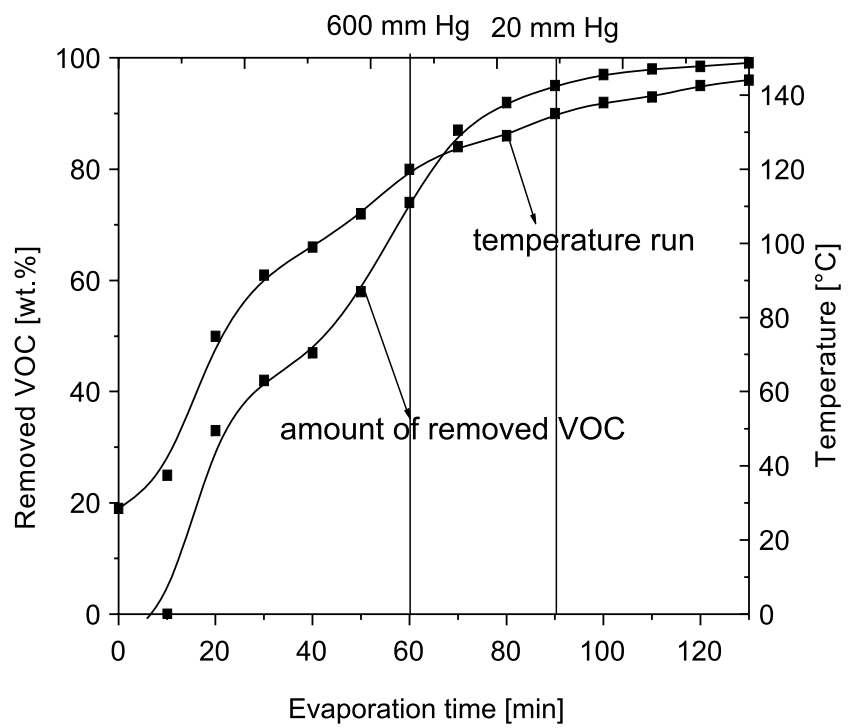

Figure 4. The temperature and the removed VOC content during the evaporation time

In the near future further possibilities have to be tested because the present process of degassing in the polymerisation reactor is not optimized with respect to the fact that acrylic PSA require special conditions during the evaporation steps.

The resultant solvent-free acrylic hot-melt PSA contains 0.4 wt.\% of VOC (organic solvent and free monomers). During the degassing process the removed VOC were examined using the Varian CP-3800 gas chromatograph (Fig. 5).

Apart from the typical adhesive parameters such as adhesive power etc., it was important to establish the relationship between the adhesive application and the cross-linking rate. The procedure was as follows in order to obtain suitable values of the performance of the solvent-free acrylic PSA.

The limits of the coat weights and the cross-linking rates using the synthesised acrylic PSA were determined. These were $60 \mathrm{~g} / \mathrm{m}^{2}$ and $120 \mathrm{~g} / \mathrm{m}^{2}$ and between 5 and $20 \mathrm{~m} / \mathrm{min}$ web speed, respectively. Peel adhesion at $20^{\circ} \mathrm{C}$ and shear strength at $70^{\circ} \mathrm{C}$ for the UV cross-linked solvent-free acrylic PSA were tested (Fig. 6). 


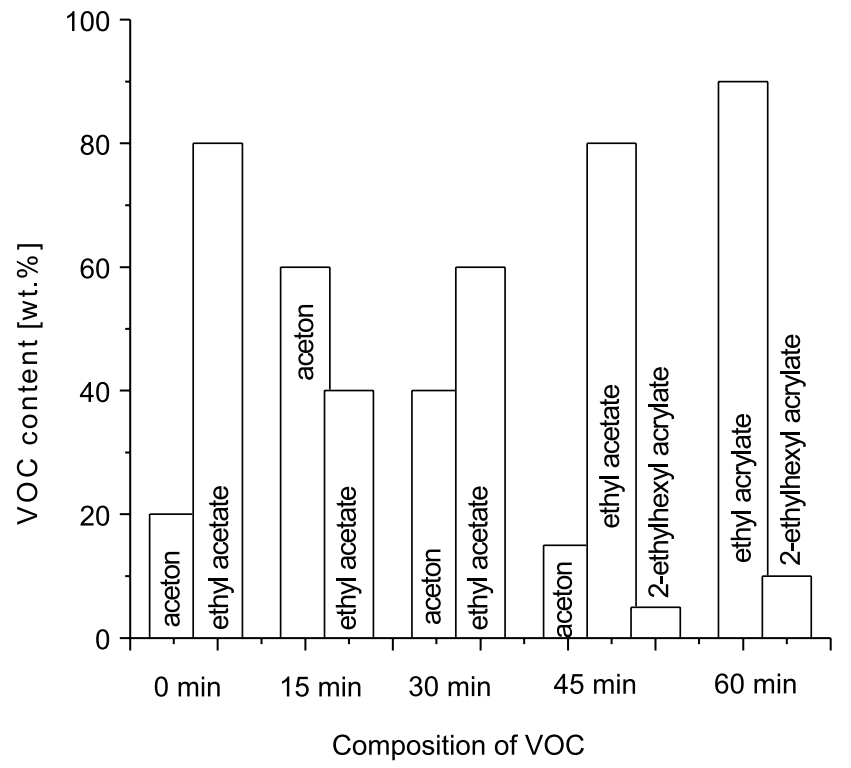

Figure 5. The composition of the VOC during the degassing process

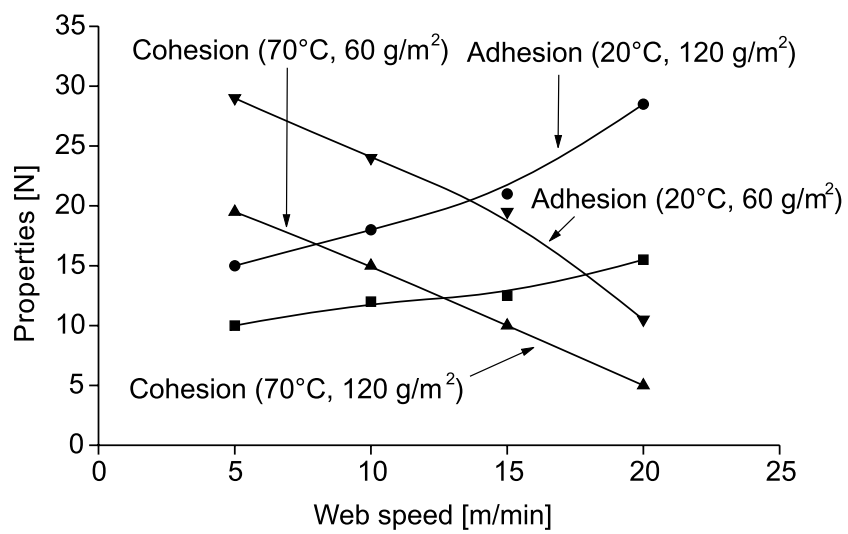

Figure 6. The influence of web speed at 60 and $120 \mathrm{~g} / \mathrm{m}^{2}$ coat weight on adhesion and cohesion

It was determined that within the various test groups (mass application/coating rate) the adhesive power at $20^{\circ} \mathrm{C}$ decreases with the increasing coating rate and the cohesion decreases with the increase of the web speed on the coating machine. The UV-crosslinked acrylic PSA demonstrate very good tack, peel adhesion and shear strength at room and at higher temperatures.

\section{Polymerisation in the twin-screw extruder and removal of volatile compounds}

The goal of radical polymerisation in the extruder is to produce the solvent-free acrylic PSA, having a conversion rate above $98-99 \%$ (residual monomer content $<1-2 \%$ ), an average molecular mass $\mathrm{M}_{\mathrm{w}}>270000$ Dalton and a perfect optical quality (free of gel particles).

It has been proposed to feed the monomers into an extruder together with a starter and polymerising it in situ. This would mean the viscous polymer being delivered from the extruder with a gear-wheel pump into a wide-slot nozzle, applied to a web and being cured by the UV exposure. An elegant solution at first glance, however as we soon discovered, also the solution with many chemical and process-engineering traps.

The influence of the screw speed of the extruder on the polymerization conversion and the PSA viscosity

The experiments were carried out in a co-rotating doublescrew extruder model LSM34GL available from Leistritz Inc.
(Germany) with eight heated zones, including a degassing zone capable of adjusting the speed of the screws and the temperature in the various zones, in a wide range. The polymerisation process in the extruder was conducted with the same monomers mixture as in the case of the synthesis in the polymerisation reactor.

The main variable technical parameter is the screw speed of the extruder. As anticipated, the polymerisation yield and the viscosity of the obtained PSA decline with the increasing screw speed as the reaction time and temperatures in the segmented zones $1-8$ are 90/90/90/100/100/110/120/120 ${ }^{\circ} \mathrm{C}$ (Fig. 7)

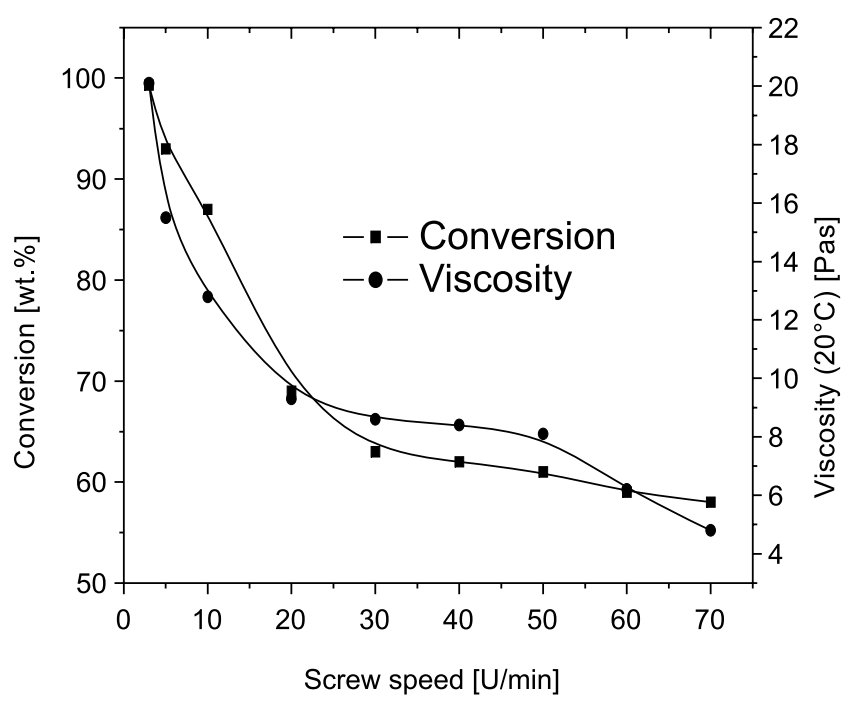

Figure 7. Polymerisation conversion and the polymer viscosity dependence on the screw speed

The best results of the polymerisation yield (99.3 wt.\%) and the viscosity of the synthesised PSA (20,3 Pa-s) were achieved with a screw speed of $3 \mathrm{rpm}$. An increase in the speed of the extruder from 10 to $70 \mathrm{rpm}$, can result in a negative effect on monomers conversion and on the acrylic PSA viscosity. The greatest weakness of the system was the degassing zone, which does not permit the removal of the residual monomers at higher screw speeds.

The UV-initiated cross-linking of extruder polymers

The results of tack, peel adhesion and shear strength of selected acrylic PSA $\left(M_{w}=421000\right.$ Dalton) coated with 60 $\mathrm{g} / \mathrm{m}^{2}$ on the polyester film and the crosslinking using the UV dose of $1000 \mathrm{~mJ} / \mathrm{cm}^{2}$, are presented in Figs. 8 and 9.

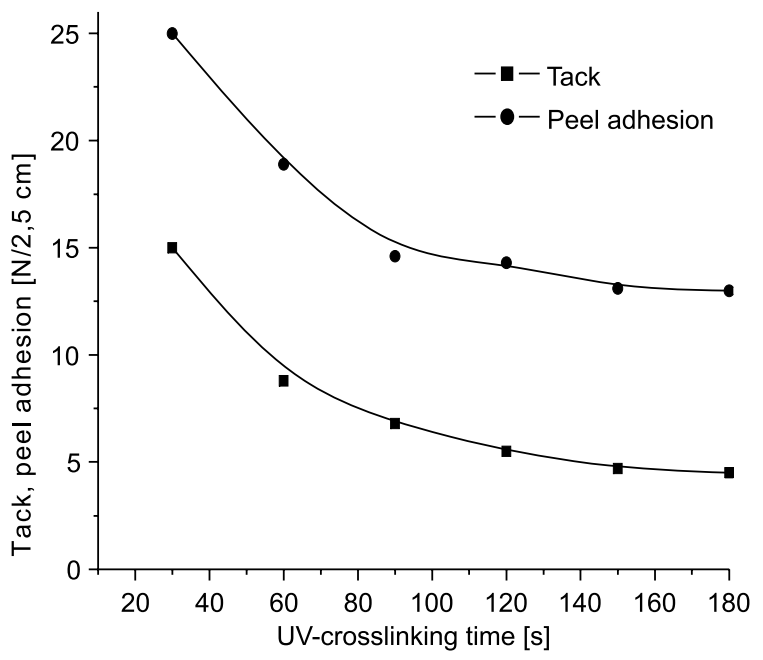

Figure 8. Tack and peel adhesion of the UV cross-linked extruded acrylic PSA 


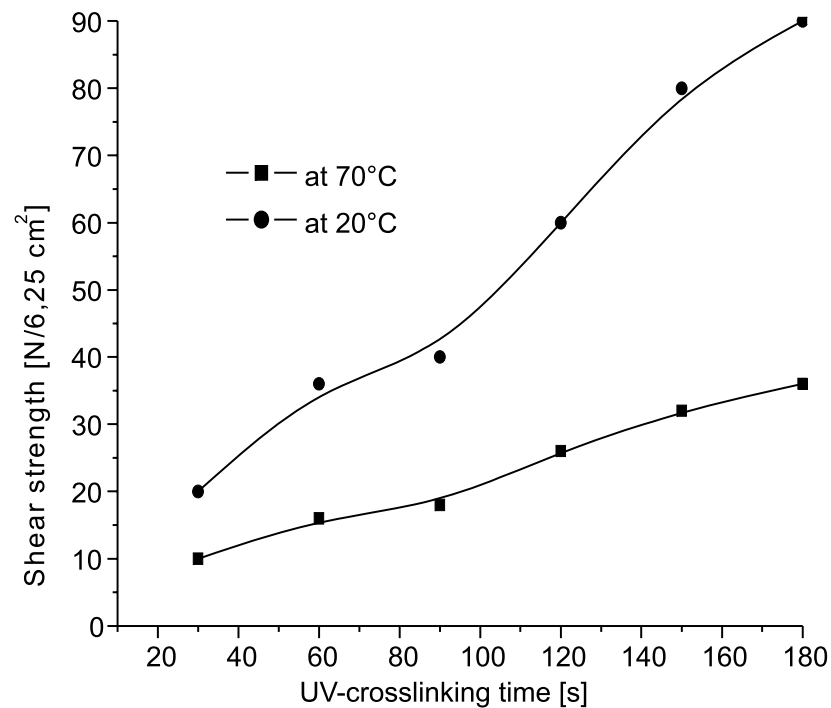

Figure 9. Shear strength of the UV cross-linked extruded acrylics PSA

The dependencies shown in Figs. 8 and 9 point out that the UV exposure time can influence tack and peel adhesion of the acrylic PSA negatively, whereas the shear strength, positively.

The observed drawbacks of mass polymerisation in the extruder were as follows:

- Gel particle content.

- The integrated degassing zone does not ensure to removal of the residual monomers completely.

- The best accepted results were achieved at very low screw speed of about $3 \mathrm{rpm}$ practically.

Polymerisation in the thin-layer evaporator and the removal of organic volatile compounds

The devolatilizing process was conducted in the thin-layer evaporator available from Fryma (Germany). The temperature was progressively increased from room temperature to the temperature between 140 and $180^{\circ} \mathrm{C}$ and the vacuum until $10 \mathrm{~mm} \mathrm{Hg}$.

During the continuous process, the acrylic PSA solution is degassed in the thin-layer and wound on a mandrel. This method is a very slow process, involving high energy and cost requirements. Therefore, its transfer onto the production scale appears unreasonable. A batch degassing process in the thinlayer evaporator can be used for small polymer charges.

\section{CONCLUSIONS}

The various methods of degassing the solvent-borne acrylic PSA described as the processes in the polymerisation reactor, thin-layer evaporator and the extruder are briefly presented in Table 1.

Table 1. The VOC concentration after the degassing of the solvent-borne acrylic PSA

\begin{tabular}{|c|c|c|c|}
\hline & $\begin{array}{c}\text { Polymerisation } \\
\text { reactor }\end{array}$ & $\begin{array}{c}\text { Thin-layer } \\
\text { evaporator }\end{array}$ & Extruder \\
\hline $\begin{array}{c}\text { VOC } \\
{[\mathrm{wt} . \%]}\end{array}$ & $0.3-0.5$ & $1.5-2.0$ & $? 3.0$ \\
\hline $\begin{array}{c}\text { Yield } \\
{[\mathrm{kg} / \mathrm{h}]}\end{array}$ & 125 & 50 & 15 \\
\hline
\end{tabular}

As expected, the use of the polymerisation reactor for the degassing of the solvent-borne acrylic PSA guarantees the lowest level of volatile organic solvent between 0.3 and 0.5 wt.\% and the residue monomers concentration. In the case of other methods used, only the thin-layer evaporator allows the production of the solvent-free acrylic PSA containing about 1.5 to $2.0 \mathrm{wt} . \%$ of the volatile organic substances for technical application. The use of the extruder for the synthesis of the solvent-borne acrylic PSA and later for the removal of solvents and residue monomers is possible only for special technical applications.

One undoubtedly positive aspect is that the solvent-free acrylic PSA are not only in harmony with the increasing concerns for the environment, but they even make a decisive contribution to reducing the strain on the environment because of their total omission or almost one hundred percent re-use of solvents.

\section{LITERATURE CITED}

1. Satas, D. (1982). Handbook of Pressure Sensitive Technology, Edited by Van Nostrand-Rheinhold Co, New York, USA.

2. Everaerts, A. \& Malmer, J., (1992). WO Patent No. 93/ 13148 3M, PCT .

3. Benedek, I. (2006). Developments in Pressure-Sensitive Products, Edited by Istvan Benedek, Taylor \& Francis a CRC Press Book, New York, USA.

4. Czech, Z. (1999). Crosslinking of acrylic pressure-sensitive adhesives, Edited by Szczecin University of Technology, Szczecin, Poland.

5. Czech, Z. (2002). Strahlenvernetzbare Lösemittelfreie Polyacrylatklebstoffe. Kautschuk Gummi Kunststoffe, 10, 492 $-501$.

6. Milker, R., Czech, Z. \& Wesołowska, M., (2007). „Synthesis of photoreactive solvent-free acrylic pressure-sensitive adhesives in the recovered system", VII Conference: „Technologie Bezodpadowe i Zagospodarowanie Odpadów w Przemyśle Chemicznym i Rolnictwie", Międzyzdroje, June, Poland. 